\title{
Differences in characteristics and exposure to stressors between persons with and without diagnosed mental illness who died by suicide in Victoria, Australia
}

Authors: Angela Clapperton(1), Stuart Newstead ${ }^{(1)}$, Lyndal Bugeja(2), Jane Pirkis ${ }^{(3)}$.

(1) Monash University Accident Research Centre, Monash University, Melbourne Australia

(2) Department of Forensic Medicine, Monash University, Melbourne Australia

(3) Melbourne School of Population and Global Health, The University of Melbourne, Melbourne Australia

\section{Corresponding author:}

Angela Clapperton

Monash University Accident Research Centre

21 Alliance Lane,

Monash University 3800

Victoria, Australia

Phone: +61399051806

Email: angela.clapperton@monash.edu

Fax: muarc-third.fax@monash.edu

\section{Biographies:}

\section{Angela Clapperton}

Angela Clapperton is a research fellow and PhD Scholar at the Monash University Accident Research Centre, Monash University. Angela has extensive experience using large injuryrelated data collections to investigate the burden of intentional and unintentional injury.

Lyndal Bugeja

Associate Professor Lyndal Bugeja has a joint appointment at Monash Nursing and Midwifery and the Department of Forensic Medicine, Monash University. She has qualifications in criminology and a research doctorate in public health.

\section{Stuart Newstead}

Stuart works at the Monash University Accident Research Centre (MUARC) as an Associate Professor. He is an Associate Director of MUARC where he leads the Centre's Injury Analysis and Data Team. He holds a PhD in Applied Statistics and is Accredited by the Statistics Society of Australia.

Jane Pirkis

Professor Jane Pirkis (PhD) is the Director of the Centre for Mental Health in the Melbourne School of Population and Global Health. She has undertaken a number of policy-relevant studies of suicide and suicide prevention, including profiling the epidemiology of suicide among the general population and at-risk groups. 


\section{Acknowledgements:}

The authors wish to thank the Coroners Court of Victoria, Australia for establishing, and allowing the authors to access, the Victorian Suicide Register data and to the staff of the Coroners Prevention Unit for their invaluable contributions in collecting the data that underpins this research. The authors also thank Dr Karen Stephan for providing advice regarding analysis methods.

\section{Abstract:}

\section{Background}

Mental illness is an established risk factor for suicide. To develop effective prevention interventions and strategies, the demographic characteristics and stressors (other than- or in addition to- mental illness) that can influence a person's decision to die by suicide need to be identified.

Aim

To examine cases of suicide by the presence or absence of a diagnosed mental illness (mental illness status) to identify differences in factors associated with suicide in the groups.

Method

Logistic regression analyses were utilised to investigate mental illness status and exposure to stressors among 2839 persons who died by suicide in Victoria, Australia (2009-2013) using the Victorian Suicide Register.

\section{Results}

Females, metropolitan residents, persons treated for physical illness/injury, those exposed to stressors related to isolation, family, work, education and substance use and those who had made a previous suicide attempt had increased odds of having a diagnosed mental illness. Employed persons had decreased odds of having a diagnosed mental illness.

Limitations

The retrospectivity of data collection; the validity and reliability of some of the data may be questionable due to the potential for recall bias.

\section{Conclusion}

The point of intervention for suicide prevention cannot always be a mental health professional; some people who die by suicide either do not have a mental illness or they have not sought help. 


\section{Introduction}

An estimated 804,000 suicides occurred worldwide in 2012 (World Health Organization [WHO], 2014). Suicide is a complex behaviour and as such the triggers or causes of suicide are also complicated. A factor established as particularly important in a number of previous studies is the presence of mental illness (Barraclough, Bunch, Nelson, \& Sainsbury, 1974; Lönnqvist et al., 1995; Isometsä, 2001; Bertolote \& Fleischmann, 2002).

Psychological autopsy (PA) studies have consistently found that $90 \%$ or more of suicides occur among persons with a diagnosed or diagnosable mental illness (Isometsä, 2001; Bertolote, Fleischmann, De Leo, \& Wasserman, 2004). However, longstanding concerns regarding the method used for PA studies have led some to claim the method can lead to erroneous results and incorrect conclusions - especially when it comes to the retrospective diagnosis of a mental illness following a person's death (Pridmore, 2015; Shahtahmasebi, 2013) as the validity of assigning mental illness diagnoses by interviewing proxies is seen by critics as inherently inaccurate and subject to bias (Hjelmeland et al., 2012; Pridmore, 2015; Selkin \& Loya, 1979; Shahtahmasebi, 2013). In contrast, more recent Australian studies using data from purpose built suicide registers or other coronial data sources - which do not make retrospective mental illness diagnosis following a person's death - have found that in approximately half of suicides, the deceased had a diagnosed mental illness (Bugeja, Milner, \& Pirkis, 2015; Judd et al., 2012; Kolves, Potts, \& De Leo, 2015) and internationally, an examination of coroners records contained in the National Suicide Registry of Malaysia found reports of mental disorder in only $22 \%$ of cases (Ali et al., 2014). These findings raise the possibility that mental illness is not present among those who die by suicide to the degree identified by the PA studies and lends support to the argument that rather than suicidal behaviour being seen as simply synonymous with mental disorder it should be examined as a behaviour that is related to but also distinct from mental illness. Individuals with mental illness have a high risk of suicide but this may be because of exposure to many other risk factors, some of which are precipitated by mental illness or which interact with it. 
Further to this, a more comprehensive understanding of the potential differences in factors associated with suicide in those with mental illness and those without mental illness is still lacking. Recent published studies using suicide registers as data sources have compared suicide cases of one 'type' (or among one group) with other suicide cases to attempt to gather important information regarding possible factors related to suicide among persons in a given group (Arnautovska, McPhedran, \& De Leo, 2015; De Leo \& Klieve, 2007; Paraschakis et al., 2012; Soole, Kolves, \& De Leo, 2014). Any research that identifies differences in suicide profiles should increase the efficacy of suicide prediction (O'Connor \& Sheehy, 1997) and developing effective prevention interventions and strategies is predicated upon understanding the stressors (other than —or in addition to-mental illness) that can influence a person's decision to die by suicide.

It is therefore important to examine suicides by the presence or absence of a diagnosed mental illness to gain a more comprehensive understanding of the potential differences in factors associated with suicide in these two groups and to determine whether persons with mental illness and those without mental illness may warrant separate consideration in future research.

This study compares the socio-demographic characteristics and exposure to potential stressors between Victorian suicides where there was, and was not, evidence available of a diagnosed mental illness prior to the death by suicide.

\section{Method}

\section{Research design}

A retrospective case series study was conducted of persons who died by suicide in Victoria, Australia during the five-year period 1 January 2009 to 31 December 2013. 


\section{Data source}

The Victorian Suicide Register (VSR) was established in 2009 by the Coroners Prevention Unit (CPU) - a specialist investigative service of the Coroners Court of Victoria $(\mathrm{CCOV})$-with the aim of providing detailed and up-to-date information on all people who die by suicide in Victoria, Australia (Sutherland et al., 2017). In accordance with the Coroners Act 2008 (Vic), all deaths where suicide is suspected must be investigated by the coroner. The information generated for these investigations comprises the most comprehensive and reliable data source available on Victorian suicides. Data in the VSR are coded based on a review of all available information. Typically the entire coronial file is available to coders, containing the coronial brief, forensic medical and scientific reports (i.e., autopsy and toxicology reports), and coroners' finding. Data is coded by persons with experience in the conduct of medico-legal investigations and trained in mortality review for the purposes of surveillance and the VSR is supported by a coding manual, data dictionary and quality framework (Bugeja, Milner, \& Pirkis, 2015; Sutherland et al., 2017).

\section{Inclusion criteria}

A case was included if the death occurred in Victoria between 1 January 2009 and 31 December 2013, the coroner determined that the intent of the deceased was suicide, or (in circumstances where the coroner did not make an explicit determination of intent) the VSR coders classified the intent of the deceased as suicide in accordance with the rules contained in the VSR coding manual, see Sutherland et al. (2017) for more information.

\section{Data collection}

The following data items recorded in the VSR were extracted into a unit record dataset. Mental illness diagnosis - defined as documented evidence of an active mental illness within 12 months of death that had been diagnosed by a medical professional (see table 1 for mental illness categories). Socio-demographics characteristics included: sex; age; LGBTI status (persons were classified as LGBTI if there was any information available anywhere in the 
Coronial Brief which indicated the person would themselves identify as LGBTI); employment status; relationship status; and location of usual residence. Physical health information included: physical illness; disability; or injury. Interpersonal stressors included: death; separation from or conflict with a partner or family member; or a partner or family member's illness. Personal stressors included those related to sexuality; isolation; or exposure to violence or abuse. Situational stressors included: work; financial; substance-related and legal stressors. Past exposure to suicide and previous history of suicide attempts were also collected. See tables 2 and 3 for a full list of included variables.

\section{Analysis}

Factors related to suicide among those with a diagnosed mental illness were examined by comparing factors present in cases of those with a diagnosed mental illness to those present in cases without a diagnosed mental illness (diagnosed mental illness status). Age was categorised into 6 age groups and all other variables were dichotomous (e.g., male/female, recorded presence of stressors as yes/no).

Univariate and multivariate logistic regression analysis including main effects of all variables was conducted using IBM SPSS version 23 to determine the association between relevant variables and mental illness status (the outcome variable was diagnosed mental illness status yes/no). Unadjusted and adjusted odds ratios were calculated as the measures of association. The final model demonstrated a good fit with a non-significant Hosmer and Lemeshow test $\chi 2(8)=5.139, p=0.743$. The model explained between $13.1 \%\left(\right.$ Cox-Snell $\left.R^{2}\right)$ and $17.5 \%$ (Nagelkerke $\mathrm{R}^{2}$ ) of the variance in the outcome variable and $65.7 \%$ of cases were classified correctly using the variables in the multivariate analysis. 


\section{Results}

Almost 3000 suicide cases were recorded in the VSR during the study period ( $n=2839)$. Males comprised three-quarters of cases $(n=2135,75.2 \%)$ and the mean age at the time of death was 45.5 years. Fifty-two percent of cases $(n=1482)$ had a documented diagnosed mental illness and 1357 cases had no documented diagnosed mental illness (47.8\%). Table 1 shows the frequency and proportion of cases assigned to each category of mental illness. Cases had a mean of 5.7 stressors recorded per case (range $0-20$, SD 3.4 ); $2.7 \%$ of cases had no stressors recorded and $14.0 \%$ had more than 10 stressors recorded. Cases with a diagnosed mental illness had a higher number of stressors recorded $(M=6.39, S D=3.56)$ than the non-mental illness cases $(M=5.00, S D=2.98 ; t(2837)=-11.221, p<0.001)$.

The ten most common specific stressors recorded for both groups were the same although the ranking differed slightly. A substance-related stressor was the most common specific stressor documented for both groups and overall - recorded for $44.0 \%$ of cases $(49.5 \%$ of cases among persons with a diagnosed mental illness and $38.1 \%$ of cases among persons with no documented diagnosed mental illness). Separation from and/or conflict with a partner were also very commonly recorded stressors, as were family conflict, current treatment for a physical condition (injury and/or illness), and stressors related to work, finances and legal issues. (Table 3 )

\section{Univariate analysis}

The association of various demographic and other characteristics with diagnosed mental illness status is shown in Table 2. Compared with those aged 40-54 years, those aged 10-24 years, $70-84$ years and $85+$ years were significantly less likely to have a diagnosed mental illness at the time of their death by suicide. A significantly higher proportion of mental illness cases than non-mental illness cases were female. Those with a diagnosed mental illness were significantly more likely than those without a diagnosed mental illness to be 
members of the LGBTI community, metropolitan residents, and have made a previous suicide attempt but less likely to be employed or in a relationship.

The association of exposure to various stressors with diagnosed mental illness status is shown in Table 3. Cases with a mental illness were significantly more likely than cases without a diagnosed mental illness to have documented evidence of at least one personal stressor; interpersonal stressor; physical stressor; situational stressor; and to have been exposed to another's suicide. With regards to specific stressors recorded, those with a mental illness were significantly more likely than those without a diagnosed mental illness to have been exposed to the following personal stressors: sexuality, isolation, abuse; interpersonal stressors: family-related and non-family related; physical stressors: injury, current treatment for a physical condition; situational stressors: work, financial, legal, education, bullying, substance-related; and to have been exposed to a family member's suicide (Table 3).

\section{Multivariate analysis}

Results of the multivariate analysis are also shown in tables 2 and 3. Two demographic factors identified in the univariate analysis were no longer significant in the multivariate analysis - LGBTI and relationship status. Compared with those aged 40-54 years, those in the youngest and oldest age groups (10-24, $70-84$ and $85+)$ were significantly less likely to have a diagnosed mental illness at the time of their death by suicide. Females and metropolitan residents had increased odds of having a diagnosed mental illness compared to males and residents of rural and regional areas, respectively. Persons who had made a previous suicide attempt had 2.4 times the odds of having a diagnosed mental illness compared to those with no documented history of suicide attempts. Conversely, employed persons had decreased odds of having a diagnosed mental illness compared to unemployed persons. (Table 2)

Several stressors were also no longer significant in the multivariate analysis. The final model identified 6 stressors which reached statistical significance as independently associated 
with mental illness status. Persons exposed to isolation, family-related, work, educational, and substance-related stressors and those receiving current treatment for a physical condition, were more likely to have a diagnosed mental illness compared to people who had not been exposed to these potential stressors. (Table 3)

\section{Discussion}

Almost 3000 suicide cases were recorded in the VSR for the study period and just over half had a documented diagnosed mental illness. Findings show there are clear differences between cases with and without a diagnosed mental illness at the time of death and demonstrate that there is a group of persons who die by suicide in Victoria who potentially require increased or varied support and intervention in the context of their mental illness, but there is also a group of persons that require prevention strategies outside this mental illness/health context.

To develop effective prevention interventions and strategies it is essential to understand the stressors (other than, or in addition to, mental illness) that can influence a person's decision to die by suicide. On average, suicide cases among those with a diagnosed mental illness had a significantly higher number of specific stressors recorded compared to cases among those with no diagnosis of mental illness. However, the stressors recorded for each group were very similar, even though the ranking of their prevalence differed. A substance-related stressor was the most common specific stressor documented for both groups but was significantly more common among the mental illness group. This finding was expected given previous evidence shows comorbidity between mental and substance use disorders is highly prevalent (Laudet, Magura, Vogel, \& Knight, 2004; Jane-Llopis \& Matytsina, 2006).

Relationship separation is also a known risk factor for suicide (Sweeper \& Halford, 2006; Ide, Wyder, Kolves, \& De Leo, 2010; Stack \& Scourfield, 2015) and previous research has found relationship separation or difficulties are common stressors experienced by those 
who die by suicide (Judd et al., 2012; O'Neill, Ennis, Corry, \& Bunting, 2017). More than onethird of those in each of the two groups in the current study had been through a relationship separation in the period prior to their suicide. However, no significant difference in the frequency of exposure to this stressor between the mental illness and non-mental illness groups was found.

Family conflict, physical treatment or illness, and stressors related to work, finances and legal issues were also very common among Victorian suicide cases. While it is not possible to realistically eliminate these stressors from people's lives, strengthening an individual's personal resources, such as self-esteem, self-efficacy and locus of control, to help cope with difficulties associated with these stressors may present an important component of suicide prevention programs (Arnautovska, McPhedran, \& De Leo, 2015). In addition, effective social support within communities could help protect vulnerable persons from suicide by building and improving social connectedness and skills to cope with difficulties when they inevitably occur (WHO, 2014).

Females, persons not in the labour force, and metropolitan residents who died by suicide in Victoria were more likely to have a diagnosed mental illness at the time of their death. Presumably, to have a mental health diagnosis these people have been in contact with mental health professionals in the time prior to their suicide, suggesting traditional mental health treatment is not always effective for the prevention of suicide - at least among some Victorians who die by suicide. A recent study, also using VSR data, found $94 \%$ of the cases with a diagnosed mental illness had contact with a health service for treatment of mental health-related issues in the 12 months leading up to their death from suicide (Bugeja, Milner, \& Pirkis, 2015). These findings emphasise that improving the quality of care for people seeking help is a factor for consideration in reducing suicides that arise as a result of, or in the context of, mental disorders. Conversely, results from the current study suggest males, employed persons and rural/regional residents who die by suicide in Victoria may be unlikely to come 
into contact with mental health professionals prior to their death. Therefore, opportunities for prevention of suicide among these people should be considered in a context other than through traditional established mental health channels. Promising interventions include restricting access to lethal means (Mann et al., 2005) and a public health intervention-a three-part documentary called Man Up which explored the relationship between masculinity and mental health, well-being and suicidality—which was found to significantly increase males' intentions to seek help for personal and emotional problems (King et al., 2018).

Those with a mental illness were significantly more likely to have been found to be exposed to a number of personal, interpersonal, physical and situational stressors. None of the stressors investigated showed reduced odds of being associated with mental illness. This is somewhat surprising as it could reasonably be hypothesised that during a police or coronial inquiry investigators may be less likely to attempt to identify additional stressors among persons who had a recorded mental illness as the mental illness may be considered to be a likely and/or sufficient reason for the suicide. However, a model previously proposed to account for the relationship between mental illness and suicide (Mishara \& Chagnon, 2011) may provide insight into the associations identified in this study. The model suggests that people who live with a mental disorder in society are more likely to have a number of important risk factors (or lack of protective factors) that have previously been found to be associated with suicide. The explanatory model posits that it is these risk factors that result in the increased risk of suicide among persons with mental illness. Therefore, it is not the symptoms of the mental disorder that result in an increased suicide risk, but rather suicide is seen as the consequence of the effects of living with a mental disorder in society (Mishara \& Chagnon, 2011). While findings from this study could be perceived as preliminary support for this explanatory model, this cannot be confirmed with a study such as this - the chronology, and potentially the contribution of factors would need to be examined. 
The results presented regarding the presence of mental illness amongst female versus male suicide cases and employed versus unemployed cases may provide valuable guidance for the development of intervention and prevention practices. Females who died by suicide had almost twice the odds of having a diagnosed mental illness compared to males and employed persons had decreased odds of having a diagnosed mental illness compared to unemployed persons. These findings may simply reflect the prevalence of mental illness in the general population considering an Australian population survey found being female or not in the labour force was associated with experience of mental disorder in the 12 months prior to the survey (Slade et al., 2009). However, the findings could suggest that when compared with suicide among males, suicide among females is more likely to occur in the context of mental illness. Similarly, when compared with suicide among the employed, suicide among the unemployed may also be more likely to occur in the context of mental illness.

Available evidence suggests there is little difference in the proportion of Australians in different regions that meet the criteria for a 12-month mental disorder ( $20 \%$ of major urban residents vs. $19 \%$ of other residents) (Australian Bureau of Statistics [ABS], 2008). Findings from the current study suggest that people who die by suicide in metropolitan areas as opposed to rural/regional areas have increased likelihood of having a diagnosed mental illness. It is unclear whether this is a result of better access to - and/or quality of - mental health care (and therefore better access to potential diagnosis). However, given the evidence of little difference in the proportion of metropolitan and rural/regional residents that meet the criteria for a mental illness diagnosis, this may be a significant finding.

In Victoria, all deaths where suicide is suspected are legally required to be investigated by the coroner, and therefore the information generated for these investigations comprises the most comprehensive and reliable data source available on suicide in Victoria. However, there are problems inherent in studies of this nature. Limitations include retrospectivity of data collection and because this data is often supplied by family members, relatives or friends, as 
well as emergency services and medical personnel, the validity and reliability of some of the data may be questionable as it is subject to recall bias and potential subjective views of the persons providing information. In addition, the absence of information in the coronial file does not guarantee that the factor of interest was not present. Detailed information regarding psychosocial and precipitating events is available for both categories of suicides (i.e., suicides among persons who have a mental illness and those who do not) and therefore there is no reason potential biases should differ between the categories - consequently, the comparisons should represent real differences. Nevertheless, the associations found in this research may not be specific for suicides but related to the differences between those with and without mental illness in the general population. A further limitation of the study relates to the classification of persons into the diagnosed mental illness and no mental illness groups. It is possible that some individuals in the 'no mental illness' group may have had a mental illness that is yet to be diagnosed. In addition, mental illnesses can develop over time, be cyclic, go through several iterations and treatments or have a precipitous onset (Bugeja, Milner, \& Pirkis, 2015) and for this study, the classification of a diagnosed mental illness only included persons with an active mental illness within 12 months of death.

In summary, this study suggests that suicide among Victorians with a mental illness may be associated with being female, unemployed and a resident of metropolitan areas. In addition, being treated for physical illness or injury, being exposed to stressors related to isolation, family, work, education and substance use and having made a previous suicide attempt may also be associated with suicide among those with a mental illness. While some of these findings may simply reflect the typical life course of those with a mental illness, future research could examine potential reasons for these discrepancies.

The research adds to the existing body of knowledge by showing that persons with mental illness and those without mental illness warrant separate consideration in future research and with regards to suicide prevention initiatives. The association between mental 
illness and suicide has been determined previously (Bertolote \& Fleischmann 2002; Bertolote, 2003; Van Orden et al., 2010), meaning that the prevention and treatment of mental disorders in the prevention of suicide is uncontested (Bertolote, Fleischmann, De Leo, \& Wasserman, 2004). However, the findings from this study imply that suicide prevention initiatives in Victoria should be tailored to those with diagnosed mental illness but also to those without, as these groups seem to exhibit different suicide risk factors.

Almost half of all people in this case series did not have a diagnosed mental illness at the time of their death, but almost all had multiple other suicide stressors recorded in the VSR. These findings lend support to the argument that suicidal behaviour should be examined as a behaviour that is related to, but also distinct from, mental illness and therefore should not be seen as simply synonymous with mental disorder it. Individuals with mental illness have a high risk of suicide but this may be because of exposure to many other risk factors, some of which are precipitated by mental illness or which interact with it.

In addition, those with a mental illness had higher odds of having a number of other stressors recorded, suggesting that it was likely that the combined effect of a number of stressors had led to the person's decision to die by suicide. Consequently, for effective prevention of suicide, practitioners working with people with mental illness need to be aware of the burden placed on their patients when they are exposed to multiple personal, interpersonal and situational stressors and must be aware that this may be a time to be vigilant regarding potential signs that the person may be contemplating and/or planning to die by suicide.

Practitioners and the general public need to be aware that some persons are dying by suicide as a response to other stressors and not in the context of a diagnosed mental illness. The message should be reinforced that simply because someone is not-or does not be appear to be experiencing symptoms of a mental illness they may still be at risk of dying by suicide, especially if they are experiencing multiple stressors. The point of intervention for 
prevention of suicide cannot always be a mental health professional because these people either do not have a mental illness or they haven't sought help. Increasing and facilitating community engagement in suicide prevention is clearly needed to attempt to reduce suicide deaths.

\section{References}

Ali, N. H., Zainun, K. A., Bahar, N., Haniff, J., Hamid, A. M., Bujang, M. A., et al. (2014). Pattern of suicides in 2009: data from the National Suicide Registry Malaysia. Asia-Pacific Psychiatry, 6(2), 217-225.

Arnautovska, U., McPhedran, S., \& De Leo, D. (2015). Differences in characteristics between suicide cases of farm managers compared to those of farm labourers in Queensland, Australia. Rural and Remote Health, 15(3), 3250.

Australian Bureau of Statistics. (2018). National Survey of Mental Health and Wellbeing: Summary of Results, 2007. Canberra, Australian Bureau of Statistics. Retrieved from http://www.abs.gov.au/ausstats/abs@.nsf/mf/4326.0.

Barraclough, B., Bunch, J., Nelson, B., \& Sainsbury, P. (1974). A hundred cases of suicide: Clinical Aspects. The British Journal of Psychiatry, 125(587), 355-373.

Bertolote, J. M. (2003). Suicide and mental disorders: do we know enough? The British Journal of Psychiatry, 183(5), 382-383.

Bertolote, J. M., \& Fleischmann, A. (2002). Suicide and psychiatric diagnosis: a worldwide perspective. World Psychiatry, 1(3), 181-185.

Bertolote, J. M., Fleischmann, A., De Leo, D., \& Wasserman, D. (2004). Psychiatric diagnoses and suicide: revisiting the evidence. Crisis, 25(4), 147-155. 
Bugeja, L., Milner, A., \& Pirkis, J. (2015). Identification and analysis of health service use and pathways to health service contact amongst persons who died from suicide in Victoria, 2009-2010. Melbourne, Coroners Court of Victoria.

De Leo, D., \& Klieve, H. (2007). Communication of suicide intent by schizophrenic subjects: data from the Queensland Suicide Register. International Journal of Mental Health Systems, 1(1), 6-14.

Hjelmeland, H., Dieserud, G., Dyregrov, K., Knizek, B. L., \& Leenaars, A. A. (2012). Psychological Autopsy Studies as Diagnostic Tools: Are They Methodologically Flawed? Death Studies, 36(7), 605-626. doi: 10.1080/07481187.2011.584015

Ide, N., Wyder, M., Kolves, K., \& De Leo, D. (2010). Separation as an Important Risk Factor for Suicide: A Systematic Review. Journal of Family Issues, 31(12), 1689-1716.

Isometsä, E. T. (2001). Psychological autopsy studies - a review. European Psychiatry, 16(7), 379-385.

Jane-Llopis, E., \& Matytsina, I. (2006). Mental health and alcohol, drugs and tobacco: a review of the comorbidity between mental disorders and the use of alcohol, tobacco and illicit drugs. Drug and Alcohol Review, 25(6), 515-536.

Jorm, A. F., Korten, A. E., Rodgers, B., Jacomb, P. A., \& Christensen, H. (2002). Sexual orientation and mental health: results from a community survey of young and middleaged adults. The British Journal of Psychiatry, 180(5), 423-427.

Judd, F., Jackson, H., Komiti, A., Bell, R., \& Fraser, C. (2012). The profile of suicide: changing or changeable? Social Psychiatry and Psychiatric Epidemiology, 47(1), 1-9.

King, K. E., Schlichthorst, M., Spittal, M. J., Phelps, A., \& Pirkis, J. (2018). Can a documentary increase help-seeking intentions in men? A randomised controlled trial. Journal of Epidemiology and Community Health, 72(1), 92-98. doi: 10.1136/jech-2017-209502. 
Kolves, K., Potts, B., \& De Leo, D. (2015). Ten years of suicide mortality in Australia: Socioeconomic and psychiatric factors in Queensland. Journal of Forensic and Legal Medicine, 36, 136-143.

Laudet, A. B., Magura, S., Vogel, H. S., \& Knight, E. L. (2004). Perceived reasons for substance misuse among persons with a psychiatric disorder. American Journal of Orthopsychiatry, 74(3), 365-375.

Lönnqvist, J. K., Henriksson, M. M., Isometsa, E. T., Marttunen, M. J., Heikkinen, M. E., Aro, H. M., et al. (1995). Mental disorders and suicide prevention. Psychiatry and Clinical Neurosciences, 49 Suppl 1: S111-116.

Mann, J. J., Apter, A., Bertolote, J., Beautrais, A., Currier, D., Haas, A., et al. (2005). Suicide prevention strategies: a systematic review. JAMA, 294(16): 2064-74.

Mishara, B. L. \& Chagnon, F. (2011). Understanding the Relationship between Mental Illness and Suicide and the Implications for Suicide Prevention. In R. C. O'Connor, S. Platt \& J. Gordon (Eds.), International handbook of suicide prevention: research, policy and practice (pp. 609-623). West Sussex, UK: Wiley-Blackwell.

O'Connor, R. C., \& Sheehy, N. P. (1997). Suicide and gender. Mortality, 2(3), 239-254.

O'Neill, S., Ennis, E., Corry, C., \& Bunting, B. (2017). Factors Associated with Suicide in Four Age Groups: A Population Based Study. Archives of Suicide Research, Feb 6:1-11. doi: $10.1080 / 13811118.2017 .1283265$.

Paraschakis, A., Michopoulos, I., Douzenis, A., Christodoulou, C., Koutsaftis, F., \& Lykouras, L. (2012). Differences between suicide victims who leave notes and those who do not: a 2-year study in Greece. Crisis, 33(6), 344-349.

Pridmore, S. (2015). Mental disorder and suicide: a faulty connection. Australian and New Zealand Journal of Psychiatry, 49(1), 18-20. doi: 10.1177/0004867414548904 
Selkin, J., \& Loya, F. (1979). Issues in the psychological autopsy of a controversial public figure. Professional Psychology, 10(1), 87-93.

Shahtahmasebi, S. (2013). Examining the Claim that $80-90 \%$ of Suicide Cases Had Depression. Frontiers in Public Health, 1, 62.

Slade, T., Johnston, A., Teesson, M., Whiteford, H., Burgess, P., Pirkis, J., et al. (2009). The Mental Health of Australians 2. Report on the 2007 National Survey of Mental Health and Wellbeing. Canberra, Department of Health and Ageing.

Soole, R., Kolves, K., \& De Leo, D. (2014). Factors related to childhood suicides: analysis of the Queensland Child Death Register. Crisis, 35(5), 292-300.

Stack, S., \& Scourfield, J. (2015). Recency of Divorce, Depression, and Suicide Risk. Journal of Family Issues, 36(6), 695-715.

Sutherland, G., Milner, A., Dwyer, J., Bugeja, L., Woodward, A., Robinson, J., et al. (2017). Implementation and evaluation of the Victorian Suicide Register. Australian and New Zealand Journal of Public Health. Online; doi: 10.1111/1753-6405.12725

Sweeper, S., \& Halford, K. (2006). Assessing adult adjustment to relationship separation: the Psychological Adjustment to Separation Test (PAST). Journal of Family Psychology, 20(4), 632-640.

Van Orden, K. A., Witte, T. K., Cukrowicz, K. C., Braithwaite, S. R., Selby, E. A., \& Joiner, T. E. (2010). The interpersonal theory of suicide. Psychological Review, 117(2), $575-600$.

World Health Organization. (2014). Preventing suicide: a global imperative. Geneva, World Health Organization. Retrieved from http://www.who.int/mental_health/suicideprevention/world_report_2014/en/. 
Table 1 Presence of mental illness diagnosis and categories of mental illness among persons who died by suicide, Victoria $2009-2013$

Mental illness diagnosis

$\mathrm{n}$

At least one diagnosed mental illness

Mood [affective] disorders

$1191 \quad 42.0$

Organic, including symptomatic, mental disorders

$24 \quad 0.8$

Mental and behavioural disorders due to psychoactive substance use

247

Schizophrenia, schizotypal and delusional disorders

$198 \quad 7.0$

Neurotic, stress-related and somatoform disorders

$424 \quad 14.9$

Behavioural syndromes (assoc. w physiological disturbances \& physical factors)

$38 \quad 1.3$

Disorders of adult personality and behaviour

Disorders of psychological development

17

Behavioural \& emotional disorders (onset usually occurring in childhood and adolescence) 
Table 2 Demographic characteristics associated with diagnosed mental illness status among persons who died by suicide, Victoria 2009-2013

\begin{tabular}{|c|c|c|c|c|c|c|}
\hline \multirow[b]{2}{*}{ CHARACTERISTICS } & \multicolumn{2}{|c|}{$\begin{array}{r}\text { No mental } \\
\text { illness diagnosis }\end{array}$} & \multicolumn{2}{|c|}{$\begin{array}{r}\text { Mental illness } \\
\text { diagnosis }\end{array}$} & \multirow[t]{2}{*}{$\begin{array}{l}\text { Unadjusted odds ratios } \\
\qquad(95 \% \mathrm{Cl} ; \mathrm{p} \text {-value) }\end{array}$} & \multirow[t]{2}{*}{$\begin{array}{r}\text { Adjusted odds ratios } \\
(95 \% \mathrm{Cl} ; \mathrm{p} \text {-value })\end{array}$} \\
\hline & $\mathrm{n}$ & $\%$ & $\mathrm{n}$ & $\%$ & & \\
\hline $10-24$ & 204 & 15.0 & 159 & 10.7 & $0.6(0.5-0.7 ; p<.001)^{\star}$ & $0.4(0.3-0.5 ; p<.001)^{*}$ \\
\hline $25-39$ & 349 & 25.7 & 424 & 28.6 & $0.9(0.7-1.1 ; p=.322)$ & 0.8 (0.7-1.0; p-.050) \\
\hline $40-54$ & 376 & 27.7 & 504 & 34.0 & 1.0 & 1.0 \\
\hline $55-69$ & 248 & 18.3 & 276 & 18.6 & $0.8(0.7-1.0 ; p=.093)$ & $0.9(0.7-1.1 ; p=.221)$ \\
\hline $70-84$ & 133 & 9.8 & 97 & 6.5 & $0.5(0.4-0.7 ; p<.001)^{\star}$ & $0.7(0.5-0.9 ; p<.020)^{*}$ \\
\hline $85+$ & 47 & 3.5 & 22 & 1.5 & $0.3(0.2-0.6 ; p<.001)^{*}$ & $0.4(0.2-0.7 ; p<.001)^{\star}$ \\
\hline Male & 1112 & 81.9 & 1023 & 69.0 & 1.0 & 1.0 \\
\hline Female & 245 & 18.1 & 459 & 31.0 & $2.0(1.7-2.4 ; p<.001)^{\star}$ & $1.9(1.5-2.3 ; p<.001)^{\star}$ \\
\hline LGBTI person & 28 & 2.1 & 62 & 4.2 & $2.1(1.3-3.3 ; p=.002)^{*}$ & $1.6(0.9-2.7 ; p=.106)$ \\
\hline Indigenous person & 11 & 0.8 & 15 & 1.0 & $1.3(0.6-2.7 ; p=.574)$ & $0.9(0.4-2.0 ; p=.782)$ \\
\hline Metropolitan resident & 802 & 59.1 & 1058 & 71.4 & $1.7(1.5-2.0 ; p<.001)^{*}$ & $1.5(1.3-1.8 ; p<.001)^{*}$ \\
\hline Employed & 696 & 51.3 & 622 & 42.0 & $0.7(0.6-0.8 ; p<.001)^{*}$ & $0.7(0.6-0.8 ; p<.001)^{*}$ \\
\hline In a relationship & 569 & 41.9 & 554 & 37.4 & $0.8(0.7-1.0 ; p=.013)^{*}$ & $0.9(0.8-1.1 ; p=.256)$ \\
\hline Prev. suicide attempt & 117 & 8.6 & 316 & 21.3 & $2.9(2.3-3.6 ; p<.001)^{*}$ & $2.4(1.9-3.1 ; p<.001)^{*}$ \\
\hline
\end{tabular}

Note. $L G B T I=$ lesbian, gay, bisexual, transgender, and intersex * = statistically significant 


\begin{tabular}{|c|c|c|c|c|c|c|}
\hline \multirow[b]{2}{*}{ STRESSORS } & \multicolumn{2}{|c|}{$\begin{array}{r}\text { No mental } \\
\text { illness diagnosis }\end{array}$} & \multicolumn{2}{|c|}{$\begin{array}{r}\text { Mental illness } \\
\text { diagnosis }\end{array}$} & \multirow{2}{*}{$\begin{array}{r}\text { Unadjusted odds } \\
\text { ratios }(95 \% \mathrm{Cl} ; \mathrm{p}- \\
\text { value) }\end{array}$} & \multirow[t]{2}{*}{$\begin{array}{l}\text { Adjusted odds ratios } \\
(95 \% \mathrm{Cl} ; \mathrm{p} \text {-value) }\end{array}$} \\
\hline & $\mathrm{n}$ & $\%$ & $\mathrm{n}$ & $\%$ & & \\
\hline Personal stressor & 474 & 34.9 & 705 & 47.6 & $1.7(1.5-2.0 ; p<0.001)^{*}$ & \\
\hline Sexuality & 34 & 2.5 & 71 & 4.8 & $2.0(1.3-3.0 ; p=0.002)^{*}$ & $1.3(0.8-2.2 ; p=0.288)$ \\
\hline Isolation & 175 & 12.9 & 266 & 17.9 & $1.8(1.5-1.2 ; p<0.001)^{*}$ & $1.3(1.0-1.6 ; p=0.038)^{*}$ \\
\hline Experience of abuse & 312 & 23.0 & 507 & 34.2 & $1.7(1.5-2.1 ; p<0.001)^{*}$ & $1.2(1.0-1.5 ; p=0.098)$ \\
\hline Interpersonal stressor & 1100 & 81.1 & 1291 & 87.1 & $1.6(1.3-1.9 ; p<0.001)^{*}$ & \\
\hline Partner & 749 & 55.2 & 848 & 57.2 & $1.1(0.9-1.3 ; p=0.277)$ & $0.9(0.8-1.1 ; p=0.244)$ \\
\hline Family & 551 & 40.6 & 857 & 57.8 & $2.0(1.7-2.3 ; p<0.001)^{*}$ & $1.5(1.3-1.8 ; p<0.001)^{*}$ \\
\hline Non-family & 277 & 20.4 & 380 & 25.6 & $1.3(1.1-1.6 ; p=0.001)^{*}$ & $0.9(0.7-1.1 ; p=0.278)$ \\
\hline Physical stressor & 588 & 43.3 & 760 & 51.3 & $1.4(1.2-1.6 ; p<0.001)^{*}$ & \\
\hline Physical illness & 367 & 27.0 & 440 & 29.7 & $1.1(1.0-1.3 ; p=0.119)$ & $1.0(0.8-1.2 ; p=0.771)$ \\
\hline Injury & 160 & 11.8 & 219 & 14.8 & $1.3(1.0-1.6 ; p=0.020)^{*}$ & $1.0(0.8-1.3 ; p=0.914)$ \\
\hline Pain & 251 & 18.5 & 309 & 20.9 & $1.2(1.0-1.4 ; p=0.116)$ & $0.9(0.7-1.2 ; p=0.446)$ \\
\hline Treatment & 408 & 30.1 & 549 & 37.0 & $1.4(1.2-1.6 ; p<0.001)^{*}$ & $1.5(1.2-1.8 ; p=0.001)^{*}$ \\
\hline Disability & 42 & 3.1 & 56 & 3.8 & $1.2(0.8-1.9 ; p=0.320)$ & $1.1(0.7-1.7 ; p=0.771)$ \\
\hline Situational stressor & 982 & 72.4 & 1205 & 81.3 & $1.7(1.4-2.0 ; p<0.001)^{*}$ & \\
\hline Work & 380 & 28.0 & 522 & 35.2 & $1.4(1.2-1.6 ; p<0.001)^{*}$ & $1.4(1.1-1.7 ; p=0.001)^{*}$ \\
\hline Financial & 392 & 28.9 & 532 & 35.9 & $1.4(1.2-1.6 ; p<0.001)^{*}$ & $1.1(0.9-1.3 ; p=0.344)$ \\
\hline Legal & 312 & 23.0 & 395 & 26.7 & $1.2(1.0-1.4 ; p=0.024)^{*}$ & $0.9(0.8-1.1 ; p=0.539)$ \\
\hline Education & 54 & 4.0 & 124 & 8.4 & $2.2(1.6-3.1 ; p<0.001)^{*}$ & $2.6(1.7-3.9 ; p<0.001)^{*}$ \\
\hline Bullying & 154 & 11.3 & 247 & 16.7 & $1.6(1.3-1.9 ; p<0.001)^{*}$ & $1.1(0.9-1.5 ; p=0.348)$ \\
\hline Substance related & 517 & 38.1 & 733 & 49.5 & $1.6(1.4-1.9 ; p<0.001)^{*}$ & $1.4(1.2-1.7 ; p<0.001)^{\star}$ \\
\hline Exposure to suicide & 130 & 9.6 & 201 & 13.6 & $1.5(1.2-1.9 ; p=0.001)^{*}$ & \\
\hline Family & 90 & 6.6 & 158 & 10.7 & $1.7(1.3-2.2 ; p<0.001)^{*}$ & $1.2(0.9-1.6 ; p=0.252)$ \\
\hline Friend & 29 & 2.1 & 29 & 2.0 & $0.9(0.5-1.5 ; p=0.735)$ & $0.8(0.4-1.4 ; p=0.430)$ \\
\hline Acquaintance & 11 & 0.8 & 20 & 1.3 & $1.7(0.8-3.5 ; p=0.172)$ & $1.6(0.7-3.6 ; p=0.262)$ \\
\hline Stranger & 3 & 0.2 & 8 & 0.5 & $2.5(0.7-9.3 ; p=0.186)$ & $1.5(0.4-6.0 ; p=0.575)$ \\
\hline
\end{tabular}

Note. ${ }^{*}=$ statistically significant 